\title{
The Sharing Economy
}

\section{A Comparison between China and Europe}

\author{
Shanxiang Xiao \\ Jiangxi Institute for Economic Administrators \\ Nanchang, Jiangxi, China
}

\author{
$\mathrm{Ti} \mathrm{Wu}$ \\ Mac., International Innovation (Entrepreneurship) \\ Co-founder and Managing Director of Avocado Adventures \\ UK \\ Birmingham, United Kingdom
}

\begin{abstract}
This paper provides a comprehensive understanding of the distinct features of sharing economy companies in China and how they differ from those in Europe. The report fills an important gap in the literature, which is deficient in explaining how the cultural and political environment of different countries impacts the sharing economy. Collaborative thinking pioneers such as Botsman and Rogers (2010), Chase (2015) as well as Liu and Wu (2016) provide theoretical framework in understanding the concept of the sharing economy and collaborative consumption. A set of extended qualitative research interviews with professionals and students with experience living in both Europe and China are presented. Themes from these discussions, which highlight the features of the sharing economy in both China and Europe, are explored. The Chinese sharing economy is in general found to be more service-based and fast moving than its European equivalent, which functions in a different framework based on concepts of community and sustainability. The importance of trust and understanding of the Chinese political system in this kind of business is highlighted. Strategies for carrying out business in the Chinese sharing economy are discussed. This paper is particularly aimed towards European companies who wish to do business within the sector of the sharing economy in China.
\end{abstract}

Keywords—sharing economy; differences; China; Europe

\section{RESEARCH QUESTION AND SIGNIFICANCE OF THE STUDY}

Although the sharing economy represents a huge market in China, even large companies that have seen success elsewhere in the world have run into difficulties in China. In March 2016, it was announced that Uber, a hugely popular car share app, would use a large share of its profits earned in other countries - a total of 1 billion dollars - to invest in the Chinese market in order to compete with the local competitor, Didi Chuxing (Da, 2016). However despite this huge investment and the popularity of the Uber model elsewhere, the bid was not successful - by August 1st, Uber's services in China were acquired by Didi Chuxing (Hern, 2016;). Uber's failure to "break" the Chinese market was commented on by both Chinese and Western media (Kong, 2016; Millward, 2016;). Didi Chuxing was then valued at an estimated 35 billion dollars after the acquisition (Hern, 2016), winning the battle once and for all. The plight of Uber in China gives rise to important questions about the success and failure of foreign sharing economy companies in China - why do some succeed while others fail? And what strategies should companies in this sector adopt to have a chance of survival?

Behind the failure and success story in the sharing economy sector are complex cultural, political and socialeconomic factors working together. Culture and society as well as the business environment in China are very different from Europe. Meanwhile, the political system is quite different from that in Europe. These variables have had a synergistic effect, leading to differences in the Chinese and European sharing economy situations.

There are extensive discussions of the sharing economy on the Internet and in the academic literature, led by business analysts, financial reporters and entrepreneurs. However, the specific national characteristics of the sharing economy in different countries have not been well studied in the academic literature. This study is aimed at exploring the influence of the multi-dimensional factors on this highly dynamic sector. The research question of the paper is:

In what aspects is the Chinese market for the sharing economy different from that in Europe? What are the distinct features of the two markets?

The specific sub-questions are as follows:

- What role do sharing economy companies play in daily life (both in China and Europe)?

- How is the Chinese marketing situation different from that in Europe?

- What Chinese characteristics make the market different?

- What strategies are effective and what should be avoided?

- What are the challenges and limitations for sharing economy companies in China?

With aims to research and identify the distinct features of the sharing economy in China and Europe, adding to the academic literature on the subject for future research and entrepreneurs interested in the Chinese and European markets, this paper is projected to be a useful guide for 
business practitioners, especially European entrepreneurs, to learn about the differences of the sharing economy in China and how to best exploit these national characteristics, identifying effective strategies and potential threats and challenges to working within this sector in China.

\section{BACKGROUND INTRODUCTION}

\section{A. The Status Quo of the Global Sharing Economy}

Sharing is one of the most ancient human behaviours (Rinne, A., et al. 2013). Ancient people shared water, hunted animals and farmed goods; modern people, for their part, share roads, schools and other public infrastructure (Trivet, 2014). In recent years, some companies have used Internet technology to build online platforms and taken sharing to a whole new level (PWC, 2015). For example, on an average day in $2015,500,000$ people shared their rooms with a stranger through Airbnb (Smith, 2015) and over one million people per day use Uber to share their private cars with strangers (Smith, 2016). The sharing economy has grown from a niche market to a mainstream social movement (Finley, 2013), which still provides huge opportunities for entrepreneurs.

In recent decades, the global sharing economy has developed at tremendous speed. A key feature of the modern sharing economy is a third party platform that allows users to share, exchange or rent out spare assets, knowledge and experiences to others (Finley, 2013; Botsman and Rogers, 2010; Koopman et al, 2015). In this study, the majority of such platforms discussed are in the form of mobile apps or occasionally desktop sites. This revolutionary business model is often known as P2P (Peer to Peer), (also known as $\mathrm{C} 2 \mathrm{C}$, Consumer to Consumer) and it has quickly changed many consumer lifestyles globally. Start-ups grew rapidly and took a big "slice of the pie" from traditional monopolies. McLean (2015) commented that two thirds of new start-ups are now trying to disrupt some traditional industry by offering a digital solution based on the sharing economy concept. Botsman and Rogers (2010) argues that the traditional way of supply and demand is changing and the relationship between sellers and buyers is disrupted. In addition, consumers are able to get the goods they want from each other and decentralized from the traditional big companies. Botsman (2011) further insisted that this macro paradigm shift would become renowned as a major achievement of the 21 st century.

\section{B. The Sharing Economy in China}

China is a massive market for the sharing economy. The marketing value of the Chinese sharing economy in 2015 is around 1.96 trillion RMB and there are as many as 500 million service providers in the Chinese sharing economy (CSIC, 2016). Moreover, the growing speed of the sharing economy in China is projected to grow at an annual speed of $40 \%$ in the next 5 years and this sector is expected to reach $10 \%$ of the total GDP of China by 2020 (Ibis, 2016).

Li Keqiang (2016), Premier of the State Council of the People's Republic of China, has commented that "the sharing economy is not an equation of adding, but multiplying. It has effectively lowered the entry barrier of entrepreneurship and innovation, makes the most of spare resources and creates powerful drivers for the nation's economy." Li further added that another characteristic of the sharing economy is that "everybody can participate in it, and everybody can benefit from it." $\mathrm{He}$ acknowledged its function in facilitating the "fair and just" in Chinese society (Gov, 2016).

Euro-centric business literature has long been accused of underestimating the innovation emerging from China, a developing country famous for its strong manufacturing base (Miller, 2013). However, this time, the rise of the sharing economy has made China a leading innovator in this industry (Leng, 2016).

\section{Different Definitions of the Sharing Economy}

The collaborative thinking pioneer Rachel Botsman (2013) commented that "The sharing economy lacks a shared definition". There are several terms which piece together to make up a bigger picture of the sharing economy. Related terms in the business literature include Collaborative Consumption, Peer Economy, Marketplace Economy, O2O (Online to Offline) and On Demand Economy.

The concept initially appeared in a 1978 paper named "Community Structure and Collaborative Consumption: A Routine Activity Approach" (Belk, 2014). The paper was written by Marcus Felson and Professor Joel Spaeth. Felson and Spaeth's definition is broad and slightly different than today's. They explained collaborative consumption as any action in which several people consume goods or services in the process of participating in joint activities with each other (Felson and Spaeth, 1978: 614). Botsman and Rogers (2011) are the pioneering scholars in this field and made the term "collaborative consumption" a buzzword (Leismann et al, 2013). Botsman and Rogers (2011) redefined collaborative consumption as a "system of organized sharing, bartering, lending, trading, renting, gifting, and swapping" (2011, p. xv). Some researchers see "collaborative consumption" and "sharing economy" as interchangeable (Radcliffe, 2014; PWC, 2014), whereas some argue that collaborative consumption is a part of the sharing economy, and some insist that it is the other way around (Botsman, 2013). In this paper, "collaborative consumption" is regarded as a social behaviour whereas'the sharing economy' is the economic model.

The term O2O (Online to Offline) gained wider popularity from a paper on TechCrunch by Alex Rampell, TrailPay CEO. He explained that $\mathrm{O} 2 \mathrm{O}$ is a business mode where users pay online and enjoy the service offline (Rampell, 2010). A lot of businesses based on the sharing economy use the $\mathrm{O} 2 \mathrm{O}$ mode. In some countries like China, investors are more familiar with the term $\mathrm{O} 2 \mathrm{O}$ instead of sharing economy (Eastday, 2016). 


\section{METHODOLOGY}

\section{A. Selection of Qualitative Method}

This paper attempts to gain a deep and complex understanding about the "behind the scenes" factors that made the Chinese sharing economy thriving. Therefore, a qualitative research approach is appropriate for this research (Robson, 2002).

Descriptive interviews are used for this research because they allow respondents to express themselves freely on any aspect of the subject and to speak about what they know. Bloom and Crabtree (2006) describe "semi-structured, indepth interviews" as useful as the sole data collection method for a qualitative research project as they allow the research to "delve deeply into social and personal matters". The "semi-structured" means that the pre-planned questions are open-ended and the interview can go in another direction according to the length and depth of answers on a certain topic. Bloom and Crabtree acknowledge that as the interviews goes on, the questions may change slightly as the interviews become more directed.

\section{B. Respondent Selection}

Ten interviews were conducted. 8 out of 10 of the participants have had experience living in both China and Europe for at least six months. Of the ten participants, eight of them are business practitioners that have worked for projects related to the sharing economy. The practitioners include executives, managers and normal staff in micro businesses and medium sized enterprises as well as multinational enterprises. The other three interviewees are graduate students with experience with sharing economy companies as consumers. Bloom and Crabtree (2006) call this deliberate interview selection "purposeful sampling".

The respondents were chosen for the richness and depth of answers that they could provide on this topic. Six of the respondents from China, three are from the UK and one is from the Netherlands. The ratio of male to female respondents is 6:4. Eight of them are aged 23 to 35, and the other two are aged 37 and 46 respectively. Since some interviewees requested anonymity, the interviewee names were replaced by codes.

The researcher used his personal, familial and friends' connections to reach the participants. The Chinese respondents were contacted via WeChat, a Chinese social network app that supports voice and video calls as well as text. The other respondents were contacted via Skype and email.

The executives and managers as well as first line staff were selected as interviewees in order to get an 'insider', in depth view of the sharing economy. The students with experience interacting with sharing economy companies shared their opinions as users. Both Chinese and European perspectives were considered. The respondents were selected from a wide range of companies, including big multinational enterprises, small and medium enterprises and startups.

\section{The Interview Procedure}

It is important to have some icebreaking time before officially conducting the interviews so that the respondents could answer more frankly (Luo, 2015). Before starting the interview, background research was done in order to get the respondents' names, genders, company details and work experience. At the beginning of the interview, the interviewer confirms this basic information with the respondent and chats casually to make the interviewee feel more relaxed and respected. For some more nervous and not very talkative interviewees, the researcher prepared some jokes or other topics to break the ice.

The first question asked is regarding their personal views and understandings of the sharing economy. It is an open question, which aims to 'warm up' the interviewee so they will be interviewee comfortable to speak out on whatever subject they wish. Follow up questions investigate their views on which types of companies are more likely to succeed in China, and what factors lead to success. This question draws on their experiences and knowledge to identify factors that are important for a Chinese sharing company. The next question asked the respondent to describe a European successful sharing economy company and identify the factors that made the company succeed.

After these questions about successful cases of both European and Chinese sharing economy companies, the researcher further investigated the respondent's opinions on what kind of business would succeed or fail in these two markets.

The interviewees outside the UK were contacted via video calls by Wechat and Skype and the ones in the UK were interviewed face to face. The researcher asked the interviewee's permission to record the interview. The interviews with Lancaster University students were conducted in Lancaster University Management School meeting room, the others were conducted in the company offices in Preston, Manchester and Birmingham. The interviews lasted between 25 minutes and one hour.

The interviews were recorded. Notes were taken during the interviews, and a more detailed transcription or translation was done afterwards. In order to ensure that there was no misinterpretation of the interviews, the researcher sent the important points to each respondent to check.

After the first few interviews, the researcher decided to adjust the interview strategy. The answers were quite stilted and the interviewees didn't seem comfortable. New strategies were taken in order to deal with these problems, using Saunders et al, 2007 as a guide.

\section{Data Analysis}

To analyse the interviews, the transcripts and notes taken were collected together, along with the 'personal profile' of each respondent. Burnard et al (2008) identifies two different approaches to analyzing interview data: The inductive and the deductive approach. In the first, the inductive approach the research has little or no theory and ideas about the issue before completing the analysis: and in the second, the 
researcher already has an idea of the theory behind the interviews and will wait to compare that theory with data and see how it compares. In this study, the researcher has chosen an inductive approach: because there is very little research done on this particular topic and the interviews are open ended, the researcher wanted to see what ideas and themes would come from the interviews before picking out any themes or theories.

With this in mind the researcher began "thematic content analysis". This important process, described as" identifying themes and categories that 'emerge from the data' "(Burnard et al, 2008), separates the similarities and differences between what exactly the respondents have said. The process was carried out by listening repeatedly to the interviews, and writing a key theme in a spreadsheet each time that it was heard, adding new themes every time and deleting ones that did not seem important after the interviews had been listened to several times. If the themes were too similar, they were merged. Since some of the questions were quite structured, it was appropriate to present some of the quotes and opinions by Table, to allow for directly comparing different opinions.

The themes were then listed descriptively in the Research Findings Section, accompanied by quotes from the respondents. The themes are then compared and discussed in the context of wider literature.

\section{RESEARCH FINDINGS AND DISCUSSION}

This section illustrates the findings and discusses the social, economic and political factors that differ between the sharing economies in Europe and in China. Seven themes were summarized throughout the interviews from the thematic content analysis, and these themes are illustrated in subsequent sections.

\section{A. THEME 1-Knowledge and Opinions of What the Sharing Economy Actually Is Differ Widely between Respondents}

The respondents differed in their daily use of the sharing economy. Of the three European respondents interviewed, they all used some desktop applications to rent cars (Zipcar), catch a ride (Blablacar) or find a room (Airbnb). The most common sharing economy company used by the respondents was Didi, with seven respondents, and Uber, with five respondents admitting to have used it. The Chinese respondents, on their part, had all used Didi. Five of the respondents were very familiar with Airbnb - one as a host and the others as guests - and one regularly used a Chinese sharing app for sharing leftover cooking or homemade meals with people in the same neighbourhood. All of the respondents accessed the internet on their smartphones.

Based on their daily experience using sharing economy services, their understanding of what the sharing economy also differs widely. The Table below shows a summary of a key idea from each interview. "Table I"

TABLE I. UNDERSTANDING OF THE SHARING ECONOMY

\begin{tabular}{|c|c|c|}
\hline Name & Company Scale & Summary of understanding of 'the sharing economy' (summary of key notes) \\
\hline RY & Less than 10 employees startup & $\begin{array}{l}\text { It is a new and modern concept based on Internet technology that enables users to share resources with } \\
\text { each other. }\end{array}$ \\
\hline$\overline{\mathrm{ZM}}$ & Less than 10 employees startup & It is a new lifestyle that promotes sharing rather than owning. \\
\hline SL & $\begin{array}{l}200 \text { employee medium sized } \\
\text { company }\end{array}$ & $\begin{array}{l}\text { It is a new business mode that enables users to pay online and enjoy the use of lots of services offline } \\
\text { and locally to them for a good price. }\end{array}$ \\
\hline JS & $\begin{array}{l}\text { Big company with more than } \\
1000 \text { employees }\end{array}$ & $\begin{array}{l}\text { It is an efficient business mode that deals with a lot of pain of many people's daily life using internet } \\
\text { technology to make their lives easier. }\end{array}$ \\
\hline KJ & $\begin{array}{l}\text { Small company with around } 30 \\
\text { employees }\end{array}$ & $\begin{array}{l}\text { It created companies value billions within a few years of foundation, there is much more value out } \\
\text { there waiting to be exploited; }\end{array}$ \\
\hline JTR & Less than 10 employees startup & $\begin{array}{l}\text { It is a platform that collects offline spare goods (including products and services) and matches them } \\
\text { with online users. }\end{array}$ \\
\hline LB & $\begin{array}{l}\text { Preparing to set up the company } \\
\text { with a team of } 3 \text { people }\end{array}$ & $\begin{array}{l}\text { It makes people's lives better and helps to deal with the conflict between people's needs and the } \\
\text { shortage of resources. }\end{array}$ \\
\hline JG & $\begin{array}{l}\text { Less than } 5 \text { employees micro } \\
\text { business }\end{array}$ & It is a mind-set that encourages sharing goods instead of owning them. \\
\hline $\mathrm{RB}$ & University Student & $\begin{array}{l}\text { It is a type of social networking platform that brings together people with the same interests and } \\
\text { allows them to share with each other. }\end{array}$ \\
\hline
\end{tabular}

Four of the ten respondents saw the sharing economy as a commercial concept and for them, the sharing economy is a mode of doing business using internet technology to deliver offline service and products to online users. Three respondents commented on the sharing economy from the functionality side and saw it as a solution to the shortage of resource, waste of under-used products and a way to easily and cheaply meet social needs. Both of these sides are essential for a flourishing sharing economy. The other three respondents saw the sharing economy as a mind-set. It is a fashion concept and modern lifestyle.

The respondents shared some of their opinions about the differences from a business practitioner point of view. Some interesting points are summarized in the following part combining with a critical analysis of the researcher. 


\section{B. THEME 2-European Customer Habits Have Rarely Changed with Time}

RY, a young entrepreneur who graduated from the UK and worked in Europe for 5 years, has commented on the differing customer habits he has experienced in both China and Europe:

"European lifestyles have not changed as much as the Chinese people's in the past decades. These developed countries have already built their stable social system where most people are used to the lifestyle that they are already enjoying. China, on the other hand, has been through so many changes in the past few decades and people's lives have been significantly changing at a high frequent rate. Under such a big, fast moving social environment, Chinese customers became more open minded in embracing internet technology and new lifestyles comparing to European ones. Another reason that the European citizens are more reluctant in accepting the online platforms is due to the consideration of data safety. The global events of personal data leaking have become a big concern of many European people. In Germany, most people are very cautious about their online identity, a number of them do not use real names on social network websites such as Facebook and Twitter. The potential threat of data leaks makes them sceptical about using mobile applications and online platforms."

In China, on the other hand, the awareness of Internet safety has not been promoted as much and normal members of the public are less concerned about sharing their personal information. It remains to be seen whether this is a factor that has allowed sharing economy companies to flourish in China.

\section{THEME 3-The Product Preference Differs}

Four (LB, KJ, JTR, KC) out of the eight respondents mentioned that companies in China provide a wide range of service types, whereas European ones focus on dealing with second hand goods or sharing new goods such as cars. For example, the leading Chinese online selling platform 58.com, formerly a second hand goods site is not only focusing on the second hand goods market anymore. The emphasis is transferred to sharing services, such as cleaning, babysitting, car rental, furniture repair and other services (Jia, 2015).

JTR: "Although there are companies in Europe that enable people to use services from peers, such as Blablacar, the majority of the sharing economy companies are product based. For example, every European knows eBay and Gumtree and lists their spare goods on these websites. A newly founded company called Shpock is aggressively expanding using mobile apps, which allows users to easily find second hand deals near them."

KJ: "In China, all kinds of different daily needs can be fulfilled via online platforms and mobile apps. For example, people use apps to get cleaners to do the cleaning, hire a chef to cook meals, get a babysitter to take care of the children and use Didi taxi to fulfil transport needs It is difficult in Europe at this stage to imagine such a lifestyle."

The following sub factors were identified by the interviewees as the main reasons for this difference:
- LB: "In Europe, sustainability and environmental awareness is much more important to consumers."

- Societal objection to second hand or used goods in China affects the sharing economy.

- Cost of goods and labour is very different in the two societies

- Trust is a key issue when it comes to the sharing economy.

\section{THEME 4-Smartphone Use and Population Density Really Matter}

In China, $53 \%$ of people use smartphones as their primary way to access the internet (Statista, 2016), which provides a technical foundation for users to access platforms and for companies to reach users. JS mentioned that "the GPS function of mobile phones makes users able to find nearby services. The high population density of modern Chinese cities ensures a high number of available service providers ." JTR also commented on the importance of the smartphone in Chinese society, especially with regard to the popular social networking app Wechat, with which users can join groups to advertise sharing products or services.

\section{E. THEME 5-Strategies that Chinese Sharing Economy Companies Adopt in Order to Succeed Are Complex}

The interviewees shared their opinions about the effective and not so successful strategies that Chinese sharing economy based internet companies used. Three strategies were mentioned for mobile apps startups, which make up the majority of sharing economy companies:

- Bribing or subsidizing the customers to use an app to increase membership;

- Ensuring service quality and user experience will improve as the company expands and scales its services;

- Utilize government policies and related regulations.

The role of Chinese government can influence companies strongly. SL stated that "Most foreign companies fail in China because they have not learned how to deal with Chinese government officials." JTR said that "Ensuring upto-date knowledge of government policies would help the entrepreneur to get resources, such as HR, workspace, incubators and subsidizes at a cheaper cost." ZM mentioned that "Xinwenlianbo (Chinese News Broadcast) might sound tedious for young and passionate entrepreneurs, but it tells you which business sectors the Chinese government pay attention to,: smart entrepreneurs can adapt promptly to the right sector at the right time and get support and subsidies from the government."

In 2015, Chinese government-backed venture funds raised around 1.5 trillion RMB (Oster, 2016). Countless incubators with government funding were built in Chinese cities (Blank, 2016). Let alone the Tier 1 big cities, Zhengzhou, a mediocre Tier 2 city has invested more than 10 billion RMB to support entrepreneurs. 105 Group Innovation 
Space (GIS) and incubators were built in the past two years and $95 \%$ of this workspace is offered free for entrepreneur applicants ( $\mathrm{Si}, 2016)$. As the Chinese government has shown enthusiasm for sharing economy companies, interested sharing economy entrepreneurs are likely to make up a large part of these applicants.

Besides free workspace, a huge amount of funding is provided for young entrepreneurs in China (Ibis, 2016).

\section{CONCLUSION}

China is a big player in the sharing economy - the market has great potential. The unique Chinese culture and distinct business environment and lifestyle have a synergistic effect on the sharing economy countries in China. More importantly, no foreign company can succeed in business for long if they do not understand Chinese politics. The qualitative research carried out here has identified the following factors that differentiate the sharing economy in China and in Europe:

- Chinese people are seen as being more amenable to internet technology. European people's concerns around internet safety slow down the development of the sharing economy companies.

- Sharing economy companies in China provide different services, whereas second hand goods exchange and renting platforms are more popular in Europe. Possible reasons behind this difference are: (1) European customers are more concerned with sustainability and environmental awareness. Therefore, people are more willing to use second hand goods. (2) Buying second hand products is not popular in China. The government and media as well as companies promote consumerist culture to facilitate economic growth. (3) Product cost in China is cheaper and the price difference between second hand and new products is small, therefore people are not willing to take the risk of getting a second hand product to save small amounts of money. Moreover, labour in China is also cheaper many people survive on low salaries; sharing economy companies provide a good platform for them to trade their skills and time for financial profit. Whereas in Europe, labourers are paid better and are generally more secure and consumers feel safer about using the traditional labour hiring system. (4) Trust is an important factor that determines the success of a business. Recent Chinese scandals have made a lot of consumers sceptical about product quality. Existing Chinese second hand product reselling platforms are experiencing problems with fraudsters selling defunct products.

- The high smartphone use rate and population density are foundations of the sharing economy. These two factors are less prominent to achieve in Europe, making them a unique aspect of sharing economy companies in China.
The following strategies are recommended for a company attempting to target the Chinese sharing economy market:

- Subsidizing the customers to participate is a commonly used approach. If the company's success is determined by the number of users, this can be a viable option. However, it is not an effective way to retain loyal customers as these people could only be attracted by the subsidies, and not by loyalty to the brand.

- Improving service quality and user experience can attract loyal users and ensure higher use frequency. Although the platforms generate new working opportunities, the service providers should be properly trained and monitored. A complete rating system is recommended in order to motivate service providers and ensure better quality.

Government policies can help the company to sense what sectors are worth investing in. Government funding and other resources can be accessible. Going against the government and not dealing with government officials appropriately would likely cause potential problems for further development.

Everybody has experience sharing with classmates, friends and relatives. Internet technology has broken down the geographical distance and stranger-awkwardness, and thus taken sharing to a whole new level (PWC, 2015). Peers can now share with others they have never met. The common medium for these companies is via mobile applications and desktop sites. The GPS function of smartphones helps users to find nearby service and products and big data technology matches demand with supply (Ben-zvi, 2016; Price, 2015). The sharing economy helps to deal with global resource shortage and under-used spare assets (Benkler, 2016). It also creates a new community for people to fulfill social needs (Gansky, 2010; Owyang, 2013).

The sharing economy in China has successfully disrupted several traditional industries, including cleaning, babysitting, car-sharing and hospitality. Consumer habits have changed significantly in recent years due to the sharing economy. As China is still a developing country, the daily needs of people are far from being fulfilled and the solutions to some of them can be found in internet digital solutions based on sharing. As Liantao Wang, the Vice President of Ganji suggested "There are 1.3 billion people in this country and Beijing is 10 times the size of San Francisco: the demand is massive and there waiting for entrepreneurs to explore (Li, 2016)." Business miracles can happen if European entrepreneurs implement their sharing economy ideas whilst adapting them to the Chinese market.

\section{REFERENCES}

[1] Belk, R. (2010). Sharing. Journal of Consumer Research, 36(5), 715734.

[2] Benkler, Y. (2016). Peer production, the commons, and the future of the firm. Strategic Organization. 
[3] Ben-Zvi, G. (2016). Big Data and Ad Tech: A Match Made in Heaven - SQream Technologies. [online] SQream. Available at: http://sqream.com/big-data-and-ad-tech-a-match-made-in-heaven/ [Accessed 12 Aug. 2016]

[4] Blank, S. (2016). China Startup Report: Torch, the World's Most Successful Startup Program. [online] Startupgrind.com. Available at: https://www.startupgrind.com/blog/china-startup-report-torch-theworlds-most-successful-startup-program-part-2-of-5/ [Accessed 17 Aug. 2016].

[5] Botsman, R. (2010). The case for collaborative consumption. [Video file]. $\quad$ Retrieved from http://www.ted.com/talks/rachel_botsman_the_case_for_collaborative consumption.html/

[6] Botsman, R., and Rogers, R. (2010). What's Mine is Yours: The Rise of Collaborative Consumption. New York: HarperCollins.

[7] Botsman, R. (2011). Why do we all own a lawnmower? [Audio file]. Retrieved http://www.bbc.co.uk/iplayer/episode/p00gdb3r/One_Planet_Archive _Why_do_we_all_o wn_a_lawnmower/.

[8] Botsman, R. (2012). The currency of the new economy is trust. [Video file.] Retrieved from http://www.ted.com/talks/rachel_botsman_the_currency_of_the_new _economy_is_trust.html/.

[9] Briefing, C. (2011). Political Influence in China's Biggest Companies Almost 100\%. [online] China Briefing News. Available at: http://www.china-briefing.com/news/2011/04/25/political-influencein-chinas-biggest-companies-almost-100.html [Accessed 17 Aug. 2016].

[10] Burnard, P., Gill, P., Stewart, K., Treasure, E., \& Chadwick, B. (2008). Analysing and presenting qualitative data. British dental journal, 204(8), 429-432.

[11] Chase, R. (2015). Peers Inc. London: Headline Publ.

[12] CSIC, (2016). 2016 Chinese Sharing Economy Development Report 2016. Chinese State Information Centre, pp.2-64.

[13] Da, D. (2016). Uber CEO: Uber: Invest the profit from global market to Chinese market. [online] 36kr.com. Available at: https://36kr.com/p/5045092.html [Accessed 18 Aug. 2016]

[14] Eastday. (2016). Monopolies emerged in the sharing economy, the risk of investment has increased. [online] Available at: http://mini.eastday.com/a/160219041742443.html?btype=index\&subt ype $=$ keji\&idx $=8 \&$ ishot $=0$ [Accessed 11 Aug. 2016] .

[15] Economist. (2016). Made in China?. [online] Available at: http://www.economist.com/news/leaders/21646204-asias-dominancemanufacturing-will-endure-will-make-development-harder-othersmade [Accessed 16 Aug. 2016]

[16] European Commission. (2016). Collaborative economy - Growth -. [online] Available at: http://ec.europa.eu/growth/singlemarket/strategy/collaborative-economy_en [Accessed 12 Aug. 2016]

[17] Felson, M. ; Spaeth, J.L (1978), Community Structure and Collaborative Consumption: A Routine Activity Approach. American Behavioral Scientist, Vol.21(4), pp.614-624

[18] Finley, K. (2013). Trust in the Sharing Economy: An Exploratory Study. Global Media and Communication, pp.3-59.

[19] Gov, (2016). Keqiang Li Defines the Sharing Economy: use spare resources to benefit everybody. [online] Chinese Government Website. Available at: http://www.gov.cn/guowuyuan/201605/25/content_5076680.htm [Accessed 11 Aug. 2016]

[20] Hern, A. (2016). Uber reverses out of China with $\$ 7$ bn sale to Didi Chuxing. [online] the Guardian. Available at: https://www.theguardian.com/technology/2016/aug/01/uber-chinadidi-chuxing [Accessed 17 Aug. 2016].

[21] Jia, J. (2015). 58 同城: 豪奢 O2O 58: big gamble on O2O. [online] Laohucaijing.com. Available http://www.laohucaijing.com/news/21199/ [Accessed 16 Aug. 2016].

[22] Kong, A. (2016). Uber Sells China Operations to Didi Chuxing. [online] WSJ. Available at: http://www.wsj.com/articles/china-s-didichuxing-to-acquire-rival-uber-s-chinese-operations-1470024403 [Accessed 17 Aug. 2016]
[23] Koopman, C., Mitchell, M. \& Thierer, A (2015)., The Sharing Economy and Consumer Protection Regulation: The Case for Policy Change, 8 J. BUS. ENTREPRENEURSHIP \& L. 529, 533

[24] Leismann, K., Schmitt, M., Rohn, H., \& Baedeker, C. (2013) Collaborative consumption: Towards a resource-saving consumption culture. Resources, 184-203

[25] Leng, C. The first country that made online taxis legal, why China? [online] Opinion.huanqiu.com. Available at: http://opinion.huanqiu.com/editorial/2016-07/9238174.html [Accessed 14 Aug. 2016]

[26] Li, K. The reality and imagination of the sharing economy. [online] 21jingji. Available at: http://www.21jingji.com/2016/4 20/zOMDA2NTNfMTM4OTUzOQ.html [Accessed 18 Aug. 2016].

[27] Liu, G. and Wu, B. The Sharing Economy 2.0. Beijing: Enterprise Management Publisher.

[28] Luo, R. When Network Doesn't Work: Strangers' Encounters and Awkwardness in Urban China. Urbanities. Vol.5 No.1 pp.38-49 (2015)

[29] McLean, M. The Rise of the Sharing Economy. [online] Scl.org Available at: http://www.scl.org/site.aspx?i=ed41847 [Accessed 11 Aug. 2016].

[30] Miller, H. J. Beyond sharing: cultivating cooperative transportation systems through geographic information science. Journal of Transport Geography, 31, pp. 296-308 (2013)

[31] Millward, S. Uber's China unit acquired by Didi in $\$ 35 \mathrm{~b}$ deal. [online] Techinasia. Available at: https://www.techinasia.com/zomg-didiuber-china-merger-confirmed [Accessed 17 Aug. 2016].

[32] Oster, S. Inside China's Historic \$338 Billion Tech Startup Experiment. [online] Bloomberg.com. Available at: http://www.bloomberg.com/news/articles/2016-03-08/china-statebacked-venture-funds-tripled-to-338-billion-in-2015 [Accessed 17 Aug. 2016].

[33] Owyang, J. The collaborative economy. Altimeter Research, pp. 1-27. (2013)

[34] Owyang, J. Report: Sharing is the New Buying, Winning in the Collaborative Economy | Web Strategy by Jeremiah Owyang | Digita Business. [online] Web-strategist. Available at: http://www.webstrategist.com/blog/2014/03/03/report-sharing-is-the-new-buyingwinning-in-the-collaborative-economy/ [Accessed 18 Aug. 2016]

[35] Porter, M. The competitive advantage of nations. New York: Free Press. (1998)

[36] Price, C. (2015). Harness mobile for the sharing economy. [online] Telegraph.co.uk. Available http://www.telegraph.co.uk/sponsored/technology/4gmobile/engaging-customers/11366290/harness-mobile-sharingeconomy.html [Accessed 12 Aug. 2016].

[37] Price John A. (1975), "Sharing: The Integration of Intimate Economics," Anthropologica, 17 (1), 3-27.

[38] PWC, (2015). The Sharing Economy Report. 1st ed. [pdf] Consumer Intelligence Series. Available at: https://www.pwc.com/us/en/technology/publications/assets/pwcconsumer-intelligence-series-the-sharing-economy.pdf [Accessed 11 Aug. 2016].

[39] Radcliffe, B. (2014). Collaborative Consumption Definition. [online Investopedia. Available at: http://www.investopedia.com/terms/c/collaborative-consumption.asp [Accessed 11 Aug. 2016]

[40] Rampell, A. (2010). Why Online2Offline Commerce Is A Trillion Dollar Opportunity. [online] TechCrunch. Available at: https://techcrunch.com/2010/08/07/why-online2offline-commerce-isa-trillion-dollar-opportunity/ [Accessed 11 Aug. 2016].

[41] Rinne, A., et al. (2013). Position Paper: Young Global Leader Sharing Economy Working Group. World Economic Forum Young Global Leaders Taskforce: Circular Economy Innovation \& New Business Models Initiative. Retrieved from http://www.slideshare.net/ CollabLab/ygl-sharing-economy-position-paper-final-june-2013/.

[42] Robson, C. (2002). Real world research: a resource for socia scientists and practitioner researchers (2nd ed.). Oxford: Blackwell. 
[43] Saunders, M., Lewis, P. and Thornhill, A. (2012). Research methods for business students. Harlow, England: Pearson.

[44] Si, D. (2016). The Difficult Situation of Zhengzhou's Innovation and Entrepreneurship Subsidies: 95\% of Space is free of rent, 10 billion $\mathrm{rmb}$ was invested. [online]. Available at: http://www.jianshu.com/p/577ac9d3c248 [Accessed 17 Aug. 2016].

[45] Smith, C. (2015). 50 Airbnb Statistics. [online] DMR. Available at: http://expandedramblings.com/index.php/airbnb-statistics/ [Accessed 11 Aug. 2016].

[46] Smith, C. (2016). How Many People Use Uber and 47 Amazing Uber Statistics. [online] DMR. Available at: http://expandedramblings.com/index.php/uber-statistics/ [Accessed 11 Aug. 2016].

[47] Smith, C. (2016). 20 Crazy Alipay Statistics. [online] DMR. Available at: http://expandedramblings.com/index.php/alipaystatistics/ [Accessed 12 Aug. 2016].

[48] Statista. (2016). PayPal: active registered accounts 2016 | Statistic. [online] Available http://www.statista.com/statistics/218493/paypals-total-activeregistered-accounts-from-2010/ [Accessed 12 Aug. 2016].

[49] Trivet, V. (2014). The Economic Factors Driving The Growth Of Sharing Economy. [online] Skift. Available at: https://skift.com/2014/01/22/the-economic-factors-driving-thegrowth-of-sharing-economy/ [Accessed 12 Aug. 2016]. 